cleared of extraneous visual information taken in between trials? Also. the higher blink rate in the first half of the rebase period suggests that Ss are clearing out visual information accumulated in the trial just completed.

In summary. the results of the present study seem consistent with research previously reported (Holland \& Tarlow, 1972: Baumstimler \& Parrot. 1971). However. the data have been interpreted in different ways (see Holland \& Tarlow, 1972). Therefore. with the effect of cognitive activity on blink rate established. it remains to investigate the reasons for the effect.

\section{REFERENCES}

Baumstimler, Y., \& Parrot, J. Stimulus generalization and spontaneous blinking in man involved in a voluntary activity. Journal of Experimental Psychology, 1971, 88, 95-102.

Brooks, L. R. The suppression of visualization by reading. Quarterly Journal of Psychology, 1967, 19, 289-299.

Duke-Elder, Sir Stewart. (Ed.) System of ophthalmology. Vol. IV. The physiology of the eye and of vision. St. Louis: Mosby, 1968.

Holland, M. K., \& Tarlow, G. Blinking and mental load. Psychological Reports, 1972, 31, 119-127.

Leask, J., Haber, R. N., \& Haber, R. B. Eidetic imagery in children: II. Longitudinal and experimental results. Psychonomic Monograph Supplements, 1969, 3(3, Whole No. 35$), 25-48$.

(Received for publication August 13, 1973.)

\title{
Steep delay of reinforcement gradient in escape conditioning with altruistic reinforcement*
}

\author{
ROBERT FRANK WEISS, JOE SHELBY CECIL \\ and MARCY J. FRANK \\ University of Oklahoma, Norman, Okla. 73069
}

Delay of altruistic reinforcement effects resemble those for conventional reinforcement in showing a decreasing monotonic gradient of response speed $(100 /$ latency $)(p<.001)$. Results were obtained in a discrete-trials escape conditioning situation, employing the simulated suffering of another person as the noxious

*This research was supported by Grant GS-27652 from the National Science Foundation to the senior author. Requests for reprints should be sent to Robert Frank Weiss, Department of Psychology, University of Oklahoma, 455 West Lindsey Street, Room 705, Norman, Okla. 73069. stimulus and his relief from suffering as the reinforcer.

Five experiments now clearly establish that human Ss will learn an instrumental conditioned response, the reinforcement for which is the deliverance of another human being from suffering (Weiss, Boyer, Lombardo, \& Stich, 1973; Weiss, Buchanan, Altstatt, \& Lombardo, 1971). They employed discrete-trials instrumental escape conditioning in which the noxious stimulus was the simulated suffering of another person and, upon presentation of a CS, S made an instrumental button-pushing response which was altruistically reinforced by cessation of the other person's suffering. 


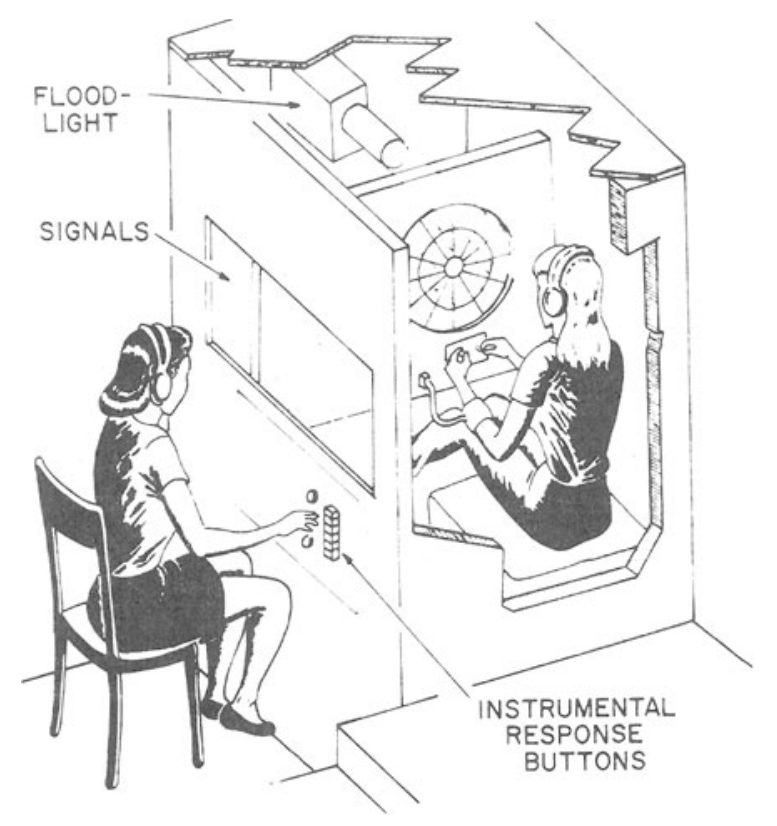

Fig. 1. Apparatus in use. The $\mathrm{V}$ is seated in a booth with her hands on the "controls" for her tracking task, facing the radar-like screen on which she monitors her performance. A flood lamp is trained on V's face, and the bracelet encircling her left forearm is the "shocker." The $S$ is shown watching $V$ through the window directly in front of herself. The $S$ is setting a masking-task evaluation dial with her right hand, and the six square buttons for the instrumental response are immediately to the right of of the dials. To the left of the window, the various signals are displayed at appropriate times. The control room is not shown and lies on the other side of the wall at S's left.

This experiment examines the gradient of delay of altruistic reinforcement upon the hypothesis that altruistic reinforcement functions in the same manner as conventional reinforcement.

\section{METHOD}

General method was identical with that used by Weiss et al (1973) to investigate other parameters. The learning contingencies were masked so that the conditioning process would not be overridden by Ss' normal use of higher processes (e.g., Spence, 1966). The experiment was represented as an aviation psychology study of skilled performance under stress and evaluation of that performance by an observer (the FAA often conducts research on campus). A victim (V), who was a confederate of E's, ostensibly received continuous painful electric shock while performing a tracking task; S's job was to observe and evaluate V's performance.

There were six Vs, all under 23 years of age, who were very well practiced for their roles from service in three related experiments. The role of the $\mathrm{V}$ was explicitly defined and was discussed and practiced together by the six Vs to maximize consistency. The role included agonized expressions, occasional verbal expression of pain, sweating, and occasional "reflex" kicking of the wall when the shock was on, and a noticeable relaxation and sigh of relief when the shock went off (the sweating, which was a particularly effective sign of stress, was achieved by overheating the V's enclosure during the "shock" period and ventilating it during the shock-off period). The $S$ and $\mathrm{V}$ were always the same sex, and groups were completely counterbalanced for V. Several ancillary techniques employed to make $\mathrm{V}$ appear genuine are described elsewhere, and were highly successful (Weiss et al, 1973).

A view of the apparatus is shown in Fig. 1, with sufficient information in caption to support the following description of conditioning procedure. Both the $\mathrm{CS}$ and the instrumental response were concealed within the "evaluation" task. Lpon presentation of a series of three "evaluation signals," S set each of three dials, each of which evaluated the V's performance on one of three criteria. Of course, such evaluations are far too complex to be used as the response to be conditioned; they were merely part of the masking task. The instrumental response to be learned was button pushing. After $\mathrm{S}$ set all three evaluation dials, he received a "report signal" (the CS) and pressed the "report buttons" (the instrumental response) ostensibly in order to record the three evaluations on magnetic tape. The onset of the "report" CS started an electric stopclock $(.01 \mathrm{sec})$ in the control room, which stopped when the first button was pressed, providing a measure of latency or starting time. Latencies were transformed into speeds (100/latency) for each trial of each S. (The time for the remaining five buttons, intended to be analogous to running time, was also measured automatically, but this measure has proven to be relatively insensitive in all studies with this apparatus, and therefore only starting time is reported.) The use of six "report buttons" was satisfactorily justified to S in terms of the three evaluation dials, there being two buttons for each dial: "The first button of each pair puts a dial identification signal on the tape; the second records the actual dial setting." The final recording was left for the end of each series of three evaluations, ostensibly so that $S$ would be free to revise his evaluations up until the end of each series.

The altruistic reinforcement followed the sixth button push: $\mathrm{V}$ received a 10 -sec break from stress after a delay regulated by an interval timer. The flood lamp (which clearly constituted part of the stress) went off; flood lamp offset signaled $V$ to breathe a sigh of relief; a "shock-off" sign lit; and the blower allowed the "nervous sweat" to visibly dry over the automatically timed 10 -sec break. Since V's booth was still lighted and the rest of the room darkened, V remained clearly visible. Of course, the flood lamp, when lit, was arranged so that it did not shine in S's eyes, and constituted no direct stress for him.

Each reinforced trial thus normally followed a cycle of shock-on, evaluation, "report" CS, instrumental "reporting" responses, and reinforcing shock-off. The procedure conforms to the paradigm of instrumental conditioning, in which "the aim of the experimenter is to arrange for the occurrence of but a single response or response chain which is followed by reinforcement," and the $\mathrm{E}$ therefore attempts to "maximize from the first the occurrence of this to-be-learned response and to minimize the occurrence of competing responses. In the maze type of instrumental situation the likelihood of competing responses occurring is reduced by having but a single straight-ahead alley instead of a number of alternative ones [Spence, 1956, pp. 37-38]." The instructions to $S$ maximized from the first the occurrence of this to-be-learned response and minimized the occurrence of competing responses. A single response chain was employed rather than a number of alternative ones.

There were four groups, with 12 Ss from the Psychology-1 pool in each group $(\mathrm{N}=48)$. Groups were completely counterbalanced for $\mathrm{V}$, and $\mathrm{S}$ and $\mathrm{V}$ were always the same sex. Exploratory research having suggested a steep gradient, the delays were 0,1 , and $2 \mathrm{sec}$, plus a no-reinforcement control group to establish a baseline. The apparatus cycle for the no-reinforcement baseline controls was identical with the experimental groups' cycle, except that the shock continued throughout the $10 \mathrm{sec}$ when the experimental groups had their reinforcing shock-off period. (Shock continuation meant that the shock-on sign remained lit, V continued to "suffer," and the flood lamp remained on.) It was predicted that the speeds of the three altruistically reinforced groups would resemble conventional reinforcement (e.g., Fowler \& Trapold. 1962) following the decreasing order $0-, 1-$. 2-sec delay, with this 
Fig. 2. Acquisition curves of response speed under different delays of altruistic reinforcement.

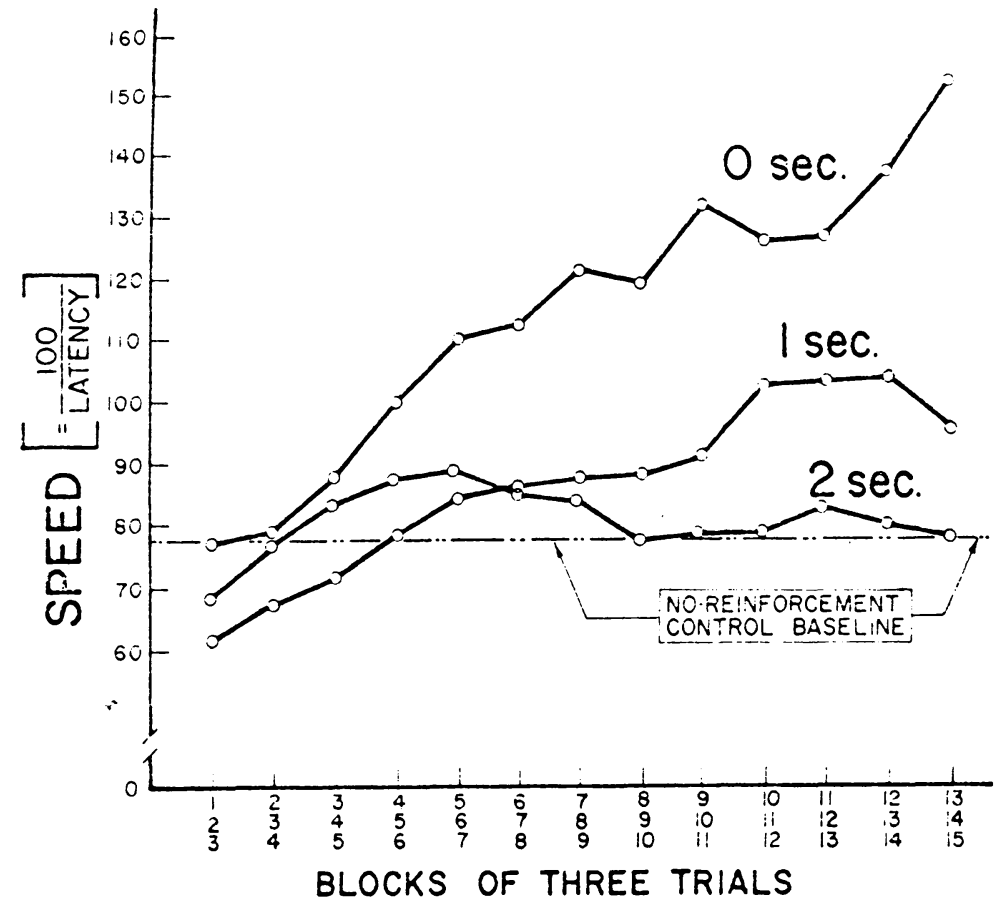

gradient probably being negatively accelerated.

\section{RESULTS}

Figure 2 shows delay of altruistic reinforcement effects which resemble those for conventional reinforcement. By the end of training, speeds for the three delay groups are clearly in the predicted rank order of $0,1,2$, with the gradient being negatively accelerated but quite steep, approaching the baseline by $2 \mathrm{sec}$.

Overall significance was evaluated by a Reinforcement Condition by Trials analysis of variance performed over all four groups for all 15 individual trials (not blocks), which indicated significant effects of trials $(F=5.01$, df $=14 / 616, \mathrm{p}<.001)$, reinforcement condition $(\mathrm{F}=3.81$, $\mathrm{df}=3 / 44, \mathrm{p}<.02)$, and their interaction $(\mathrm{F}=2.06, \mathrm{df}=$ 42/616, $p<.001)$. The study's basic hypothesis, delay effects with altruistic reinforcement, was evaluated by means of a Jonckheere test (e.g., Jonckheere, 1954; Kirk, 1968), an elegant test ideally suited for testing the significance of the rank ordering of groups and the differences between them in a single operation. Results of a Jonckheere test over a block of the last three trials indicated that the speeds of the three delay groups were significantly different from each other in the predicted order: $0,1,2(\mathrm{z}=3.144, \mathrm{p}<.001)$. The no-reinforcement controls were a suitable baseline: they did not show any significant trials effect $(F=1.17$, df $=$ $14 / 154)$ or any suggestion of a trend. This result, together with the results of all three previous experiments with no-reinforcement controls (Weiss et al, 1973), where all tests over trials were $F<1$, permitted the minimization of variability in the graphic depiction of the baseline by plotting the mean speed over all trials. The delay groups each learned the response: (a) $0 \mathrm{sec}, \mathrm{F}$ $=4.19, \mathrm{df}=14 / 154, \mathrm{p}<.001$; (b) $1 \mathrm{sec}, \mathrm{F}=2.95, \mathrm{df}=$
$14 / 154, \mathrm{p}<.001 ;$ (c) $2 \mathrm{sec}, \mathrm{F}=1.56, \mathrm{df}=14 / 154$, $\mathrm{p}<.09$. The 2 -sec delay interval was a fortunate choice, in that it seems to approximate the end point of the finite delays for this steep gradient. Acquisition is obvious over the first five trial blocks, but ceases thereafter.

\section{DISCUSSION}

Altruistic reinforcement resembles conventional reinforcement in exhibiting a decreasing negatively accelerated delay gradient. While the steepness of the gradient may be a mere artifact of apparatus or procedure, it exhibits an interesting consistency with magnitude of altruistic reinforcement (Weiss et al, 1973) where V's suffering must be reduced by more than half in order to obtain performance superior to no-reinforcement controls. Thus, the threshold value for effective reinforcement (e.g., Campbell, 1955; Tarpy, 1969) is quite high for both delay and magnitude of altruistic reinforcement.

\section{REFERENCES}

Campbell, B. A. The fractional reduction in noxious stimulation necessary to produce "just noticeable" learning. Journal of Comparative \& Physiological Psychology, 1955, 48, 141-149.

Fowler, H., \& Trapold, M. A. Escape performance as a function of delay of reinforcement. Journal of Experimental Psychology, 1962, 63, 464-467.

Jonckheere, A. R. A distribution-free k-sample test against ordered alternatives. Biometrika, 1954, 41, 133-145.

Kirk, R. E. Experimental design: Procedures for the behavioral sciences. Belmont, Calif: Cole, 1968.

Spence, K. W. Behavior theory and conditioning. New Haven: Yale University Press, 1956.

Spence, $K$. W. Cognitive and drive factors in the extinction of the conditioned eyeblink in human subjects. Psychological Review, 1966, 73, 445-458

Tarpy, R. M. Reinforcement difference limen (RDL) for delay in shock escape. Journal of Experimental Psychology, 1969, 79, 116-121.

Weiss, R. F., Boyer, J. L., Lombardo, J. P., \& Stich, M. H. Altruistic drive and altruistic reinforcement. Journal of Personality \& Social Psychology, 1973, 25, 390-400.

Weiss, R. F. Buchanan, W., Altstatt, L., \& Lombardo, J. P. Altruism is rewarding. Science, $1971,171,1262-1263$.

(Received for publication August 13, 1973.) 